\title{
Lipid profile among Moroccan overweight women and breast cancer: a case-control study
}

This article was published in the following Dove Press journal:

International Journal of General Medicine

4 June 2013

Number of times this article has been viewed

\section{Fatima Zahra Laamiri' \\ Azzedine Otmani ${ }^{2}$ \\ Samir Ahid ${ }^{1,3}$ \\ Amina Barkat ${ }^{\prime}$}

'Faculty of Medicine and Pharmacy/ Research Team in Maternal and Child Health and Nutrition, Mohammed V-Souissi University, Rabat, Morocco; ${ }^{2}$ National Institute of Oncology, Rabat, Morocco; ${ }^{3}$ Pharmacy Unit, National Institute of Oncology, Rabat, Morocco

Correspondence: Amina Barkat Research Team in Maternal and Child Health and Nutrition, Faculty of Medicine and Pharmacy of Mohammed V-Souissi University, Rabat, Morocco Email barakatamina@yahoo.fr
Background: Breast cancer has become the most common type of cancer in Morocco. In 2005, 127 new cases in women, representing $33.5 \%$ of female cancers, were added to the National Center of Oncology registry. The incidence of breast cancer is higher in Morocco than in the three other Maghreb countries, and it is significantly lower than in Western countries where it stands at over 80 cases per 100,000 people.

Purpose: This 2-year long case-control study was conducted to assess the causal relationship between the lipid profile of overweight Moroccan women and breast cancer risk.

Patients and methods: Overweight female patients with breast cancer $(n=400)$ were compared to 400 healthy controls at the National Institute of Oncology of Rabat. The epidemiological data on the disease and physical activity were gathered by interviewing the patients who had their lipid profile measured (total cholesterol, triglycerides, high density lipoprotein cholesterol, and low density lipoprotein cholesterol). Body mass index was used to determine if patients were overweight.

Results: Univariate analysis revealed a significant association between breast cancer and high body mass index (odds ratio $[\mathrm{OR}]=1.31 ; 95 \%$ confidence interval $[\mathrm{CI}]=1.25-1.37$ ), menopause $(\mathrm{OR}=2.68 ; 95 \% \mathrm{CI}=2-3.55)$, lack of physical activity $(\mathrm{OR}=0.26 ; 95 \% \mathrm{CI}=0.21-0.31)$, and triglyceridemia $(\mathrm{OR}=3.78 ; 95 \% \mathrm{CI}=2.73-5.23)$. Multivariate analysis revealed that the statistically significant increase in breast cancer risk was associated with a higher body mass index $(\mathrm{OR}=1.11 ; 95 \% \mathrm{CI}=1.04-1.18)$, menopause $(\mathrm{OR}=9.11 ; 95 \% \mathrm{CI}=4.76-17.47)$, and high triglyceride levels $(\mathrm{OR}=4.5 ; 95 \% \mathrm{CI}=2.94-6.88)$. However, a protective effect for physical activity was detected $(\mathrm{OR}=0.35 ; 95 \% \mathrm{CI}=0.26-0.48)$.

Conclusion: This study suggests that there is a connection between hypertriglyceridemia, obesity, and breast cancer risk and confirms a protective role for physical activity on breast cancer risk.

Keywords: breast cancer, lipid profile, dietary fat intake, overweight, physical activity

\section{Introduction}

Despite significant advances in cancer therapy and mammography screening among women aged 50-70 years, breast cancer remains the leading cause of cancer mortality for women in both developed countries $(30 \%)$ and developing countries $(14 \%)^{1}$ where its incidence rates have been continuously rising. ${ }^{2}$ Breast cancer is a disease characterized by prevalence, aggressiveness, unequal geographic distribution, and an increasing incidence throughout the world. . $^{3,4}$ Environmental factors, including a nutritious diet, either alone or in combination, have been incriminated in the increase in cancer incidence rates and in its progressive spread into all regions of the world. Many experimental, clinical, 
and epidemiological studies have revealed that a number of factors influence breast cancer etiology. Hormonal factors, ${ }^{5,6}$ reproductive factors, genetic factors, lifestyle, and dietary factors, ${ }^{7}$ such as obesity and high fat diet-induced obesity, are among the key factors that have been studied so far. Yet, the negative effects of overweight, obesity, and dietary lipids on breast oncogenesis has been a neglected area of research, not only in Morocco, but elsewhere as well. No articles by Moroccan medical researchers in this area have been submitted for publication. This study therefore aims to refocus attention on this neglect and to serve as a first step in the assessment of the relationship between lipid profiles, overweight, and breast cancer among Moroccan women.

\section{Patients and methods}

This case-control study was carried out over a period of 24 months at Sidi Mohammed Ben Abdellah National Institute of Oncology, Rabat, Morocco. This Institute, which is part of the Ibn Sina University Hospital of Rabat, Morocco, is dedicated exclusively to fighting cancer.

\section{Patients}

\section{Inclusion criteria}

The study included a population of Moroccan women (selected between December 2008 and December 2010) who were divided into two groups: a group of patients diagnosed with breast cancer in oncology consultations recruited at the National Institute of Oncology of Rabat and a group of breast cancer-free controls recruited at the same Institute within the framework of the cancer screening campaign organized by government authorities after having undergone a mammography that showed no signs of breast cancer. To ensure maximum compatibility between cases and controls, and to ensure a representative sample of the target group, healthy women were selected from the same group that gave rise to the cases. In order to avoid any misinterpretation of the findings, each case was matched with one control of the same age. The subjects recruited for this study were aged between 22 and 75 years and were divided into three age groups (22-34 years, 35-44 years, 45 years and over). The subjects provided informed consent to participate in this study. All information from medical records and clinical interviews with both patients and healthy controls was fed into a data entry form. The epidemiological data collected included: (a) age, (b) place of residence, (c) menopausal status (for this study, menopause is defined as amenorrhea $\geq 12$ months), and (d) physical activity. One of the aims of the questionnaire was to collect detailed information about physical activity, using as a frame of reference the definition put forth by the World Health Organization, namely, "any bodily movement produced by skeletal muscles that requires energy expenditure", 8 with particular emphasis on (a) workplace-related activities, particularly manual activities, (b) activities required to fulfill household chores and shopping, (c) recreational activities such as sports, (d) a sedentary lifestyle which is referred to as being the "performance of less than 30 minutes of physical activity per day", 9 and (e) overweight which was measured at diagnosis by Quetelet Index ${ }^{9}$ or body mass index (BMI; weight in kilograms divided by height in meters squared).

\section{Exemption criteria}

Women with chronic diseases such as high blood pressure, diabetes, and coronary heart disease were excluded as they were likely to compromise the biochemical profile. Women who were not within the age range of 22-75 years, and patients who were prescribed a treatment (chemotherapy, radiation therapy, hormone therapy) were also exempted from the study.

\section{Biochemical tests}

Biochemical tests were carried out in the biochemical laboratory at the National Institute of Oncology using a Hitachi 912 automatic analyzer (Hitachi Ltd, Tokyo, Japan). Serum lipid measurements were determined from fresh serum samples drawn after a 12 hour overnight fast. Total cholesterol (CT), triglycerides (TG), and high density lipoprotein (HDL) cholesterol were determined by standard enzymatic methods using sampling kits marketed by Roche (Basel, Switzerland). The levels of low density lipoprotein (LDL) cholesterol were indirectly calculated from the results of CT and TG using Friedewald's classical formula:

$$
\begin{aligned}
\mathrm{LDL}-\mathrm{C}= & (\text { Total cholesterol })-(\mathrm{HDL} \text { cholesterol }) \\
& - \text { Triglycerides } / 2.2 \text { for } \mathrm{mmol} / \mathrm{L} \text { or } \\
& \text { triglycerides } / 5 \mathrm{in} \text { grams } / \mathrm{L} .
\end{aligned}
$$

The mean levels of CT, TG, HDL cholesterol, and LDL cholesterol are 3.61-5.16 mmol/L, 0.45-1.71 mmol/L, 1.15$1.93 \mathrm{mmol} / \mathrm{L}$, and $0-3.35 \mathrm{mmol} / \mathrm{L}$, respectively. The results were validated by a daily quality control using normal sera control (Precinorm U [Roche]) and pathological serum control (Precipath U [Roche]) introduced into a series of assays.

\section{Statistical analysis}

The biological and epidemiological parameters collected in survey forms were stored, coded, analyzed using the Statistical Package for Social Sciences (SPSS) v13.0 (IBM 
Corporation, Armonk, NY, USA), and then subjected to bivariate and multivariate analyses. For bivariate analysis, the comparison of the means for quantitative and qualitative variables was carried out using Student's $t$-test and Pearson's Chi-square test, respectively. The results were expressed as mean \pm standard deviation or in count and percentage.

For multivariate analysis, the variables collected from the study were tested for their potential relationship with breast cancer. During the first stage, each variable was assessed independently by univariate analysis which was adjusted for age, and during the second stage, all variables were fed into a multiple regression model to assess the odds ratios. A threshold of $P<0.05$ was considered significant.

\section{Results}

Eight hundred women were included in this study and were divided into two populations: a population of 400 women with breast cancer and a population of 400 women who were breast cancer-free. Table 1 shows that the average age was $45.51 \pm 11.25$ years in the group of controls and $45.83 \pm 11.05$ years in the group of patients $(P=0.685)$. BMI was determined for each patient. The mean BMI was significantly higher in the patient group $\left(28.35 \pm 4.36 \mathrm{~kg} / \mathrm{m}^{2}\right.$ versus $\left.24.4 \pm 3.22 \mathrm{~kg} / \mathrm{m}^{2}, P<0.001\right)$. Figure 1 shows that there is a prevalence of obesity in the 22-34 years and in the 45 years and over age groups in the control group and in

Table I Demographic and epidemiological characteristics of control and breast cancer patients

\begin{tabular}{|c|c|c|c|}
\hline \multirow[t]{2}{*}{ Characteristics } & \multicolumn{2}{|l|}{$N=400$} & \multirow[t]{2}{*}{$P$-value } \\
\hline & $\begin{array}{l}\text { Control } \\
\text { patients }\end{array}$ & $\begin{array}{l}\text { Breast cancer } \\
\text { patients }\end{array}$ & \\
\hline \multicolumn{4}{|c|}{ Age group (years) } \\
\hline 22 to 34 & $64(16.8 \%)$ & $60(15 \%)$ & 0.843 \\
\hline 35 to 44 & $112(28 \%)$ & $108(27 \%)$ & \\
\hline 45 and over & $224(56 \%)$ & $232(58 \%)$ & \\
\hline \multicolumn{4}{|c|}{ Menopausal status } \\
\hline No & $240(60 \%)$ & 144 (36\%) & $<0.001$ \\
\hline Yes & $160(40 \%)$ & $256(64 \%)$ & \\
\hline \multicolumn{4}{|l|}{ Physical activity } \\
\hline Low (sedentary) & $132(33 \%)$ & $308(77 \%)$ & $<0.001$ \\
\hline Moderate & $76(19 \%)$ & $68(17 \%)$ & \\
\hline High & $192(48 \%)$ & $24(6 \%)$ & \\
\hline \multicolumn{4}{|c|}{ Body mass index (BMI) group } \\
\hline Low & $4(1 \%)$ & $8(2 \%)$ & $<0.001$ \\
\hline Moderate & $256(65.3 \%)$ & 76 (19.2\%) & \\
\hline Overweight & $108(27.6 \%)$ & $160(40.4 \%)$ & \\
\hline Obese & $24(6.1 \%)$ & $152(38.4 \%)$ & \\
\hline
\end{tabular}

Notes: Values are expressed as mean \pm standard deviation or in count and percentage. For body mass index (BMI) groups: low $\mathrm{BMI}=<18.5 \mathrm{~kg} / \mathrm{m}^{2}$; normal $\mathrm{BMI}=18.5$ to $<25 \mathrm{~kg} / \mathrm{m}^{2}$; overweight $\mathrm{BMI}=25$ to $<30 \mathrm{~kg} / \mathrm{m}^{2}$; obese $\mathrm{BMI}=>30 \mathrm{~kg} / \mathrm{m}^{2}$. the 35-44 years and the 45 years and over age groups in the population with breast cancer.

The distribution of patients according to menopausal status shows that the percentage of menopausal women in the patient group is statistically higher than in the control group (64\% versus $40 \%, P<0.001)$.

The distribution of patients according to the intensity of physical activity shows that the physical inactivity rate was higher in the patient population than in the control population ( $77 \%$ versus $33 \%, P<0.001)$. Table 2 describes the biochemical characteristics of the two groups. The average triglyceride level was significantly higher in patients with breast cancer than in healthy women irrespective of age $(1.41 \pm 0.62 \mathrm{mmol} / \mathrm{L}$ versus $1.08 \pm 0.43 \mathrm{mmol} / \mathrm{L}, P<0.001)$. However, there was no statistically significant difference between the two groups with respect to CT, HDL cholesterol, and LDL cholesterol. The results recorded in Table 3 shows that the number of women with hypertriglyceridemia in the normal weight, overweight, and obese groups was significantly higher in the population with breast cancer than in the control population. The data in Table 4 shows that (a) BMI increases the risk for breast cancer 1.31 fold $(95 \%$ confidence interval $[\mathrm{CI}]=1.25-1.37)$, which is a statistically significant increase $(P<0.001)$, (b) menopause increases the risk of breast cancer 2.68 fold $(95 \% \mathrm{CI}=2.00-3.55)$, and (c) physical activity decreases breast cancer risk 0.26 fold (95\% CI $=0.21-0.31)$. With respect to the lipid biomarkers, this study highlights a significant correlation between triglycerides and breast cancer (odds ratio $[\mathrm{OR}]=3.78,95 \%$ $\mathrm{CI}=2.73-5.23$ ). However, CT, HDL cholesterol, and LDL cholesterol were not identified as markers of breast cancer risk. All variables that were significantly associated with the incidence of breast cancer were then fed into multivariate regression analysis (Table 5) to generate an odds ratio. This analysis highlighted that a significant increase in risk was associated with $\mathrm{BMI}(\mathrm{OR}=1.11,95 \% \mathrm{CI}=1.04-1.18)$, menopausal status $(\mathrm{OR}=9.11,95 \% \mathrm{CI}=4.76-17.47)$, and triglycerides $(\mathrm{OR}=4.5,95 \% \mathrm{CI}=2.94-6.88)$. However, physical activity was a protective factor $(\mathrm{OR}=0.35,95 \%$ $\mathrm{CI}=0.26-0.48)$.

\section{Discussion}

This study highlights the culpability of overweight in breast carcinogenesis and disruption of the lipid profile, including blood triglycerides, in female patients. This study involved 400 patients with breast cancer. This is an admittedly small sample size and may not be representative of the largest number of patients admitted to the National Institute of 


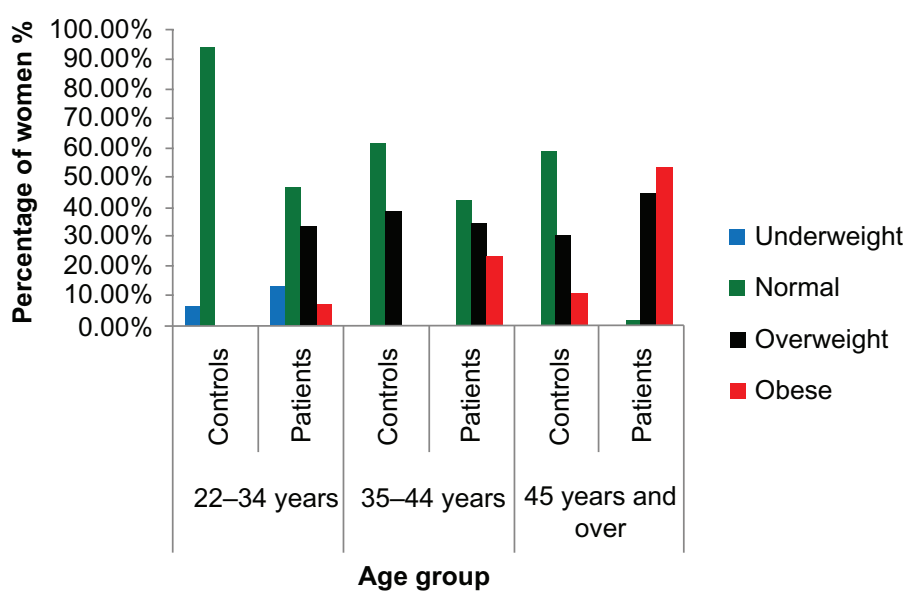

Figure I Distribution of age groups of patients and controls according to body mass index.

Oncology of Rabat. Yet, this study narrowed down the sample size of patients and used a selection bias toward those who have not undergone a therapeutic treatment (chemotherapy, radiotherapy, or any other therapy) as they could skew the results of the biochemical tests. The analysis of the general features of the patients with breast cancer shows that patients aged over 45 years, with a mean age of 45.83 \pm 11.05 years, were the most affected age group, and this

Table 2 Biochemical characteristics of control and breast cancer patients

\begin{tabular}{lll}
\hline Lipid parameters & $\mathbf{N}=\mathbf{4 0 0}$ & \\
\cline { 2 - 3 } & $\begin{array}{l}\text { Control } \\
\text { patients }\end{array}$ & $\begin{array}{l}\text { Breast cancer } \\
\text { patients }\end{array}$ \\
\hline $\begin{array}{l}\text { Cholesterol in mmol/L } \\
\text { Cholesterol level }\end{array}$ & $4.56 \pm 0.74$ & $4.58 \pm 0.82$ \\
Low & $40(10 \%)$ & $36(9 \%)$ \\
Moderate & $336(84 \%)$ & $244(61 \%)$ \\
High & $24(6 \%)$ & $120(30 \%)$ \\
Triglyceride in mmol/L & $1.08 \pm 0.43$ & $1.41 \pm 0.62 *$ \\
Triglyceride level & & \\
Low & $64(16 \%)$ & $36(9 \%)$ \\
Moderate & $332(83 \%)$ & $316(79 \%)$ \\
High & $4(1 \%)$ & $48(12 \%)$ \\
HDL cholesterol & $1.44 \pm 0.31$ & $1.44 \pm 0.31$ \\
in mmol/L & & \\
HDL cholesterol levels & & $116(29 \%)$ \\
Low & $56(14 \%)$ & $260(65 \%)$ \\
Moderate & $320(80 \%)$ & $24(6 \%)$ \\
High & $24(6 \%)$ & $2.65 \pm 1.06$ \\
LDL cholesterol & $2.58 \pm 0.69$ & \\
in mmol/L & & $300(75.8 \%)$ \\
LDL cholesterol levels & & $96(24.2 \%)$ \\
Low & $364(91.9 \%)$ & \\
High & $32(8.1 \%)$ & \\
\hline Not & & \\
\hline
\end{tabular}

Notes: Values are expressed as mean \pm standard deviation or in count and percentage. Significance threshold $P<0.05$. $*$ This result was statistically significant. Abbreviations: HDL, high density lipoprotein; LDL, low density lipoprotein. is an age range that coincides with menopause which is a period marked by many physiological and hormonal changes in women. The results recorded in Tables 4 and 5 show that menopause significantly increases the risk of breast cancer irrespective of age. This may be attributed to the increase in the prevalence of risk factors associated with breast cancer among menopausal women. The prevalence of obesity was significantly higher among the breast cancer population when compared with the control population (38.4\% versus $6.1 \%$, $P<0.001$, Table 1) and therefore obesity is incriminated as a cause in the rise in breast cancer incidence. This is consistent with data in the literature which views obesity as a breast cancer risk factor. ${ }^{10}$ In a prospective study involving 99,039 postmenopausal women, Ahn et $\mathrm{al}^{11}$ focused on the association between adiposity and weight change with incidence of breast cancer. The results of this study are (a) weight gain is partly responsible for breast cancer, (b) BMI was associated with an increased risk of breast cancer, especially among women who were not on menopausal

Table 3 Distribution of women with hypertrigyceridemia according to body mass index in the control and patient population

\begin{tabular}{lll}
\hline $\begin{array}{l}\text { Body mass } \\
\text { index }\end{array}$ & $\begin{array}{l}\text { Women with } \\
\text { hypertriglyceridemia } \\
\text { in the control } \\
\text { population } \\
\mathbf{N = 4}\end{array}$ & $\begin{array}{l}\text { Women with } \\
\text { hypertriglyceridemia } \\
\text { in the patient } \\
\text { population } \\
\mathbf{N}=\mathbf{4 8}\end{array}$ \\
\hline $\begin{array}{l}\text { Underweight } \\
\text { group }\end{array}$ & $0 \%$ & $0 \%$ \\
$\begin{array}{l}\text { Normal weight } \\
\text { group }\end{array}$ & $0 \%$ & $5.3 \%^{*}$ \\
$\begin{array}{l}\text { Overweight } \\
\text { group } \\
\text { Obesity group }\end{array}$ & $3.7 \%$ & $7.5 \%^{*}$ \\
\hline
\end{tabular}

Note: Significance threshold $P<0.05$. *These results were statistically significant. 
Table 4 Risk factors for breast cancer analyzed by univariate analysis

\begin{tabular}{llll}
\hline Variables & $\begin{array}{l}\text { Odds } \\
\text { ratio }\end{array}$ & $\begin{array}{l}\text { 95\% confidence } \\
\text { interval }\end{array}$ & P-value \\
\hline Body mass index & $1.3 \mathrm{I}$ & $\mathrm{I} .25-1.37$ & $<0.00 \mathrm{I}$ \\
Physical activity & 0.26 & $0.21-0.3 \mathrm{I}$ & $<0.00 \mathrm{I}$ \\
Menopause & 2.68 & $2.00-3.55$ & $<0.00 \mathrm{I}$ \\
Total cholesterol & 1.12 & $0.71-1.7 \mathrm{I}$ & 0.624 \\
Triglycerides & 3.78 & $2.73-5.23$ & $<0.00 \mathrm{I}$ \\
HDL cholesterol & 0.85 & $0.28-2.57$ & 0.778 \\
LDL cholesterol & 1.26 & $0.84-1.88$ & 0.256 \\
\hline
\end{tabular}

Note: Odds ratio has been adjusted for age by univariate logistic regression. Abbreviations: HDL, high density lipoprotein; LDL, low density lipoprotein.

hormone therapy, and (c) all women not on hormone replacement therapy and who gained weight between 35 and 50 years of age had a 1.4 fold increased risk of developing breast cancer.

Our findings are consistent with the results reported in this study. ${ }^{10}$ We observed that the age group (45 years and over) that was most affected by breast cancer coincided with menopause and had a higher prevalence of obesity (Table 1), and that high BMI significantly increased breast cancer risk (Tables 4 and 5). In a randomized study, the Women's Intervention Nutrition Study ${ }^{12}$ reports that (a) a decrease in the risk of breast cancer treated at an early stage has been observed as a result of a reduction in dietary fat intake, (b) this beneficial impact appears to be associated with a moderate weight loss and an improvement in insulin resistance, ${ }^{12}$ (c) the deleterious effect of fat intake which is associated with an increase in estradiol levels was confirmed in a meta-analysis, ${ }^{13}$ and (d) excess weight could promote the development of breast cancer through multiple mechanisms, ${ }^{14}$ including:

- a variation in endogenous hormone concentrations (insulin, insulin-like growth factors [IGF], and sex hormones) that could alter the balance between cell growth and apoptosis, ${ }^{15}$

- hyperinsulinism which activates a cascade of intracellular mitogenic and antiapoptotic signaling pathways, ${ }^{16}$

Table 5 Risk factors for breast cancer identified by multivariate analysis

\begin{tabular}{llll}
\hline $\begin{array}{l}\text { Associated } \\
\text { variables }\end{array}$ & $\begin{array}{l}\text { Odds } \\
\text { ratio }\end{array}$ & $\begin{array}{l}\text { 95\% confidence } \\
\text { interval }\end{array}$ & P-value \\
\hline Body mass index & I.II & $1.04-1.18$ & 0.002 \\
Physical activity & 0.35 & $0.26-0.48$ & $<0.001$ \\
Menopause & $9.1 \mathrm{I}$ & $4.76-17.47$ & $<0.00 \mathrm{I}$ \\
Triglycerides & 4.5 & $2.94-6.88$ & $<0.00 \mathrm{I}$ \\
\hline
\end{tabular}

Note: Odds ratio has been adjusted for age by multivariate logistic regression.
- insulin resistance which leads to a decrease in sex hormonebinding globulin (SHBG) by inhibiting its production in liver cells, ${ }^{17,18}$ a decrease in insulin-like growth factor binding protein (IGFBP) and hence an increase in the unbound and biologically active fraction of hormone related proteins (IGF-I/IGFBP and estradiol, testosterone/ SHBG). However, the relationship between estradiol levels and breast cancer risk has been well documented.

Again, our findings in this study reinforce these results. We found that among the healthy population, the percentage of women engaged in moderate and intense physical activity was statistically higher. Conversely, the physical inactivity rate was statistically higher among the patient population, and this is a statistically significant difference when compared with the healthy population $(P<0.001)$. Physical activity decreased breast cancer risk 0.26 fold $(95 \% \mathrm{CI}=0.21-0.31)$ and was also a protective factor $(\mathrm{OR}=0.35,95 \% \mathrm{CI}=0.26-0.48)$. Our results concur closely with the available data in the literature that stress the importance of physical activity as a means for primary prevention of cancers, including breast cancer. ${ }^{19}$ Most of the prospective studies and a substantial number of case-control studies which have evaluated the relationship between physical activity and breast cancer risk report a decreased risk ranging from $20 \%$ to $70 \%-80 \%$. A state of the art review on research carried out between 1994 and 2006 about the relationship between breast cancer risk and physical activity confirms these results. ${ }^{20}$ The immediate beneficial effects of physical activity can be attributed to a decrease in fat mass, ${ }^{21}$ and a decrease in insulin resistance and insulin ${ }^{22}$ (for the same blood glucose sample) by increasing firstly insulin sensitivity ${ }^{23}$ and then SHBG, which when bonded with testosterone and estradiol, reduces their biologically active free fraction. ${ }^{22}$ Analysis of the biochemical test results revealed that the levels of triglycerides were statistically higher in the patient group when compared to the control group $(1.41 \pm 0.62 \mathrm{mmol} / \mathrm{L}$ versus $1.08 \pm 0.43 \mathrm{mmol} / \mathrm{L} ; P<0.001)$. Likewise, hypertriglyceridemia was more common among overweight and obese patients than among healthy women with similar body structure. Nonetheless, this study could not demonstrate significant variations in the mean levels of CT, HDL cholesterol, and LDL cholesterol whose values were consistent with the reference values for both groups. Moreover, the percentage of women with high cholesterol levels in the patient group was higher than in the control group (30\% versus $6 \%$ ), but this was not a statistically significant difference $(\mathrm{OR}=1.12 ; 95 \% \mathrm{CI}=0.7-1.71, P=0.624)$. An increase in LDL cholesterol was also observed in $24.2 \%$ of the patients as opposed to $8.1 \%$ of controls, which was not 
statistically significant. This does not concur with data from the literature about a possible relationship between increased levels of LDL cholesterol and the risk of developing breast cancer. A French study ${ }^{24}$ demonstrated that high levels of transfatty acids (TFA) in blood almost double a woman's chance of developing breast cancer. TFA are unsaturated fatty acids found in animal fats, and particularly in food products such as pastries and margarine. TFA ${ }^{24}$ increase LDL cholesterol. Similarly, the recently published E3N cohort study highlighted the culpability of LDL cholesterol by focusing on effects of different types of fatty acids on the development of breast cancer. ${ }^{25}$ Researchers from Inserm and Institut Gustave Roussy conducted an epidemiologic study ${ }^{25}$ on a cohort of 363 women diagnosed with breast cancer after a blood sample was analyzed where they compared the serum fatty acid levels with those of 702 breast cancer-free controls. Other studies, similar to this, report that "good" cholesterol, or HDL cholesterol, makes it possible to measure the risk of breast cancer development among overweight postmenopausal women. According to a Norwegian study, ${ }^{26}$ overweight postmenopausal women with a low level of "good" or HDL cholesterol have a higher risk of developing breast cancer. Although "good" or HDL cholesterol plays no direct role in breast cancer, researchers at the Norwegian University of Troms $\varnothing^{26}$ concede that it promotes screening of women with significantly high androgen levels. Androgens (male sex hormones), including testosterone, are linked with the development of breast cancer and would result in a decrease in HDL levels. According to research studies of 39,000 patients carried out over 20 years, ${ }^{26}$ women who have the highest HDL levels, though overweight, have nearly less than one-third the risk of developing cancers than those with very low levels of HDL. The very low level of "good" cholesterol among these women can serve as a clue for the medical profession as to the possible presence of a breast tumor. In general, given the interwoven nature of cancer, exploring the association between dietary fat and breast cancer is a long and difficult process. The lag time between exposure and cancer manifestation is several decades and it is therefore very hard to correctly determine and measure exposure. Moreover, the complexity of the multiple risk factors, both exogenous and endogenous, creates extra difficulties in measuring the responsibility of each factor. The present study is the first to address the association between lipid profiles and overweight Moroccan women. There are two noteworthy limitations of this study: (a) the number of patients and controls enrolled was small and (b) it was conducted in a shorter period of time than is typical of studies which focus on the similar issues. Nevertheless, one of its strengths lies in providing a platform to bring together more collaborators (clinicians and researchers) to carry out a more in-depth study.

\section{Conclusion}

The arguments put forth in this case-control study incriminate obesity and dietary fat as breast cancer risk factors. Obesity prevalence was higher in the patient group than in the control group and the difference was statistically significant. Physical activity exerts an undeniable protective effect on breast cancer. The analysis of the results of lipid parameters (CT, TG, HDL-C, LDL-C) used as markers of a diet based on nutrient-rich foods showed a significant disruption in the lipid profile which involved a triglyceride dosage in the group of women with breast cancer. The data gathered through this study highlight the necessity for sustainable lifestyle practices that are geared toward decreasing energy intake through a balanced diet and regular physical activity to reduce the risk of breast cancer. Prospective studies involving biomarker analysis and dietary questionnaires among populations with different dietary habits are needed to bring to light the role that nutrients, in particular dietary lipids, play in mammary carcinogenesis among Moroccan women.

\section{Acknowledgments}

We thank all participants for taking part in this study.

\section{Disclosure}

The authors declare no conflict of interest in this work.

\section{References}

1. Hill C, Doyon F. La fréquence des cancers en France en 2002 et son évolution depuis 1968 [The frequency of cancer in France in year 2002, and trends since 1968]. Bull Cancer. 2006;93:7-11. French.

2. Brettes JP, Mathelin C, Gairard B, Bellocq JP, editors. Épidémiologie - Alimentation, lipidome et cancers du sein [Epidemiology, food, lipidome and breast cancer]. In: Cancer du sein. Issy-lesMoulineaux: Elsevier Mason; 2007:13-28. French.

3. Sasco AJ. Epidemiology of breast cancer: an environmental disease? APMIS. 2001;109(5):321-332.

4. Parkin DM, Bray F, Ferlay J, Pisani P. Global cancer statistics, 2002. CA Cancer J Clin. 2005;55(2):74-108.

5. Curado MP, Edwards B, Shin HR, et al. Cancer Incidence in Five Continents. Lyon: World Health Organization and International Association of Cancer Registries; 2007. Available from: http://www.iarc.fr/en/publications/pdfs-online/epi/sp160/CI5vol9-A.pdf. Accessed April 5, 2013.

6. Beral V; Million Women Study Collaborators. Breast cancer and hormone-replacement therapy in the Million Women Study. Lancet. 2003;362:419-427.

7. Layde PM, Webster LA, Baughman AL, Wingo PA, Rubin GL, Ory HW. The independent associations of parity, age at first full term pregnancy, and duration of breastfeeding with the risk of breast cancer. Cancer and Steroid Hormone Study Group. J Clin Epidemiol. 1989;42:963-973.

8. Caspersen CJ, Powel KE, Christenson GM. Physical activity, exercise, and physical fitness: definitions and distinctions for health-related research. Public Health Rep. 1985;100(2):126-131. 
9. Lee IM, Djoussé L, Sesso HD, Wang L, Buring JE. Physical activity and weight gain prevention. JAMA. 2010;303(12):1173-1179

10. Lahmann PH, Hoffmann K, Allen N, et al. Body size and breast cancer risk: findings from the European Prospective Investigation into Cancer and Nutrition (EPIC). Int J Cancer. 2004;111:762-771.

11. Ahn J, Schatzkin A, Lacey JV, et al. Adiposity, adult weight change, and postmenopausal breast cancer risk. Arch Intern Med. 2007;167: 2091-2102.

12. Blackburn GL, Wang KA. Dietary fat reduction and breast cancer outcome: results from the Women's Intervention Nutrition Study (WINS). Am J Clin Nutr. 2007:86:s878-s881.

13. Wu AH, Pike MC, Stram DO. Meta-analysis: dietary fat intake, serum estrogen levels and the risk of breast cancer. J Natl Cancer Inst. 1999;91: 529-534

14. Renehan AG, Roberts DL, Dive C. Obesity and cancer: pathophysiological and biological mechanisms. Arch Physiol Biochem. 2008;114: $71-83$.

15. Larsson SC, Wolk A. Excess body fatness: an important cause of most cancers. Lancet. 2008;371:536-537.

16. Dossus L, Kaaks R. Nutrition, metabolic factors and cancer risk. Best Pract Res Clin Endocrinol Metab. 2008;22:551-571.

17. Plymate SR, Jones RE, Matej LA, Friedl KE. Regulation of sex hormone binding globulin (SHBG) production in HepG2 cells by insulin. Steroids. 1988;52:339-340.

18. Crave JC, Lejeune H, Brebant C, Baret C, Pugeat M. Differential effects of insulin and insulin-like growth factor I on the production of plasma steroid-binding globulins by human hepatoblastoma-derived (Hep G2) cells. J Clin Endocrinol Metab. 1995;80:1283-1289.
19. International Agency for Research on Cancer. Weight Control and Physical Activity. Lyon: World Health Organization; 2002. Available from: http://www.iarc.fr/en/publications/pdfs-online/prev/handbook6/ handbook6.pdf. Accessed April 5, 2013.

20. Monninkhof EM, Elias SG, Vlems FA, et al; TFPAC. Physical activity and breast cancer: a systematic review. Epidemiology. 2007;18:137-157.

21. Williams PT. Nonlinear relationships between weekly walking distance and adiposity in 27,596 women. Med Sci Sports Exerc. 2005;37: 1893-1901.

22. Duclos M. Physical activity and breast and colon cancer: evidence-based physical activity. Sci Sports. 2009;24(6):273-280

23. Barnard RJ, Ngo TH, Leung PS, Aronson WJ, Golding LA. A low-fat diet and/or strenuous exercise alters the IGF axis in vivo and reduces prostate tumor cell growth in vitro. Prostate. 2003;56:201-206.

24. Jean-Luc Goudet. Cancer du sein: les acides gras trans fortement suspectés [Breast cancer: trans fatty acids strongly suspected]. Futura sciences. 2008. French. Available from http://www.futura-sciences.com/ $\mathrm{fr} /$ news $/ \mathrm{t} /$ medecine $/ \mathrm{d} /$ cancer-du-sein-les-acides-gras-trans-fortementsuspectes_15218-1/. Accessed May 15, 2013.

25. Thiébaut AC, Chajès V, Clavel-Chapelon F, Gerber M. [Unsaturated fatty acids intake and breast cancer risk: epidemiological data review]. Bull Cancer. 2005;92(7):658-69. French [with English abstract].

26. Razis E, Kosmidis P, Aravantinos G, et al. Second line chemotherapy with 5 fluorouracil and vinorelbine in anthracycline and taxane pretreated patients with metastatic breast cancer. Cancer Invest. 2004;22: $10-15$.
International Journal of General Medicine

\section{Publish your work in this journal}

The International Journal of General Medicine is an international, peer-reviewed open-access journal that focuses on general and internal medicine, pathogenesis, epidemiology, diagnosis, monitoring and treatment protocols. The journal is characterized by the rapid reporting of reviews, original research and clinical studies across all disease areas.

\section{Dovepress}

A key focus is the elucidation of disease processes and management protocols resulting in improved outcomes for the patient. The manuscript management system is completely online and includes a very quick and fair peer-review system. Visit http://www.dovepress.com/ testimonials.php to read real quotes from published authors. 